Article

\title{
Preparation and Properties of Alkali Activated Metakaolin-Based Geopolymer
}

\author{
Liang Chen ${ }^{1,2, *}$, Zaiqin Wang ${ }^{1,2}$, Yuanyi Wang ${ }^{1,2}$ and Jing Feng ${ }^{1,2}$ \\ 1 Materials and Structural Department, Changjiang River Scientific Research Institute, Wuhan 430010, China; \\ wangzq@mail.crsri.cn (Z.W.); wangyuanyi@mail.crsri.cn (Y.W.); fengjing@mail.crsri.cn (J.F.) \\ 2 Collaborative Innovation Center for Geo-Hazards and Eco-Environment in Three Gorges Area, \\ Yichang 443002, China \\ * Correspondence: chenliang@mail.crsri.cn; Tel.: +86-27-8282-0957
}

Academic Editors: Arie van Riessen and Claudio Ferone

Received: 14 May 2016; Accepted: 2 September 2016; Published: 8 September 2016

\begin{abstract}
The effective activation and utilization of metakaolin as an alkali activated geopolymer precursor and its use in concrete surface protection is of great interest. In this paper, the formula of alkali activated metakaolin-based geopolymers was studied using an orthogonal experimental design. It was found that the optimal geopolymer was prepared with metakaolin, sodium hydroxide, sodium silicate and water, with the molar ratio of $\mathrm{SiO}_{2}: \mathrm{Al}_{2} \mathrm{O}_{3}: \mathrm{Na}_{2} \mathrm{O}: \mathrm{NaOH}: \mathrm{H}_{2} \mathrm{O}$ being 3.4:1.1:0.5:1.0:11.8. $\mathrm{X}$-ray diffraction (XRD) and Fourier transform infrared spectroscopy (FT-IR) were adopted to investigate the influence of curing conditions on the mechanical properties and microstructures of the geopolymers. The best curing condition was $60{ }^{\circ} \mathrm{C}$ for $168 \mathrm{~h}$, and this alkali activated metakaolin-based geopolymer showed the highest compression strength at $52.26 \mathrm{MPa}$. In addition, hollow micro-sphere glass beads were mixed with metakaolin particles to improve the thermal insulation properties of the alkali activated metakaolin-based geopolymer. These results suggest that a suitable volume ratio of metakaolin to hollow micro-sphere glass beads in alkali activated metakaolin-based geopolymers was $6: 1$, which achieved a thermal conductivity of $0.37 \mathrm{~W} / \mathrm{mK}$ and compressive strength of $50 \mathrm{MPa}$. By adjusting to a milder curing condition, as-prepared alkali activated metakaolin-based geopolymers could find widespread applications in concrete thermal protection.
\end{abstract}

Keywords: alkali activated; geopolymer; metakaolin; curing condition; thermal insulation

\section{Introduction}

Alkali activated geopolymers have attracted increasing attention in recent years for their potential uses as construction materials and environmentally cementitious binders that would partly replace ordinary Portland cement (OPC) [1,2]. Studies have shown that geopolymers have excellent mechanical properties [3], such as high early strength and low shrinkage [4,5]. In addition, geopolymers also can be used as construction panels and fire resistant materials [6] for their characteristic light weight and thermal insulation properties [7-9]. Geopolymers can be produced from many materials, even waste materials. Metakaolin, fly ash, kaolin, and slag are the typical raw materials for the preparation of geopolymer composites [10].

Metakaolin is a de-hydroxylated form of the clay mineral kaolinite with 4-, 5-, and 6-coordinated aluminum ions in alumina polyhedron sheet structures [11]. Metakaolin is also a valuable admixture with many excellent advantages, including porosity, high specific area, good absorbability and strong coordinative bonds when stimulated [12]. The initial reaction process and performance of alkali activated metakaolin-based geopolymer is not only influenced by the chemical composition [13], 
dosage and concentration of raw materials [14-16] but also affected by the curing conditions during the early-age polymerization process $[17,18]$.

In addition to the above characteristics, one of the applications of geopolymers is its use as a protective coating material. As a type of inorganic polymeric silicate material with three-dimensional network structure based on covalent and ionic bonds, geopolymers have the advantages of strength, excellent mechanical properties and adjustable setting time. The excellent acid and alkali corrosion resistance and high temperature resistance properties of geopolymers are absent in most common organic concrete protective materials. Therefore, alkali activated metakaolin-based geopolymers may also have potential application prospects in concrete surface protection $[19,20]$.

In this paper, an alkali activated metakaolin-based geopolymer was prepared with metakaolin, sodium hydroxide, sodium silicate and water. The formulation of raw materials for the geopolymer was studied using an orthogonal experimental design. The influence of curing temperature and time on the mechanical properties and microstructures of alkali activated metakaolin-based geopolymers were investigated by X-ray diffraction (XRD) and Fourier transform infrared spectroscopy (FT-IR). In addition, hollow micro-sphere glass beads (HMGB) were mixed with metakaolin particles to improve the thermal insulation property of the alkali activated metakaolin-based geopolymer. The internal morphologies, thermal conductivity and compressive strength of different HMGB modified geopolymers were studied. We also explored the interfacial properties and durability of prepared glass bead modified geopolymers as a coating on concrete. The results suggest that by adjusting the curing condition to a milder condition, as-prepared alkali activated metakaolin-based geopolymers could find widespread applications in concrete thermal protection.

\section{Experimental Methods}

\subsection{Characterization}

The composition of metakaolin powder was determined by X-ray Fluorescence (Axios advanced, PANalytical B.V., Almelo, The Netherlands) after tabletting treatments. The micro-morphologies of the alkali activated geopolymer were analyzed with scanning electron microscopy (SEM, JSM-6610LA, JEOL Ltd., Tokyo, Japan). The compressive strength of the samples (cube mold, $20 \mathrm{~mm} \times 20 \mathrm{~mm}$ $\times 20 \mathrm{~mm}$ ) after curing were measured on a universal force tester (AG-IC 100KN, Shimadzu, Kyoto, Japan) at a sliding velocity of $1 \mathrm{~mm} / \mathrm{min}$. In the compressive strength measurements, three parallel samples were tested for each specimen. FT-IR measurements were performed by a Bruker TENSOR27 spectrometer (Bruker Optik GmbH, Ettlingen, Germany) after the cured geopolymers were ground into powder. The X-ray diffraction (XRD) patterns were also measured on geopolymer powder over the scattering $2 \theta$ angle range $10^{\circ}-90^{\circ}$ using CuK $\alpha$ radiation $\left(\lambda \mathrm{k} \alpha_{1}=1.54056 \AA, \lambda \mathrm{k} \alpha_{2}=1.54439 \AA\right)$ with a step-size of $0.0194^{\circ}$ at $25{ }^{\circ} \mathrm{C}$ (D8 Advance, Bruker). The adhesive strength was tested by PosiTest pull-off tester (DeFelskoAT-A, Ogdensburg, NY, USA) according to ISO 4624/16276-1. The thermal conductivity of $10 \mathrm{~cm}$ thick alkali activated geopolymer coating was determined by a thermal conductivity measuring apparatus (QTM-500, Kyoto Electronics Manufacturing Company, Kyoto, Japan). Artificial weathering aging tests were performed according to ISO 4892-2 with a Xenon Test Chamber (Q-SUN Xe-1-S, Q-Lab Corporation, Westlake, OH, USA). The irradiance was set at $0.51 \mathrm{~W} / \mathrm{m}^{2}$ with $340 \mathrm{~nm}$ wavelength. The inside temperature of the chamber remained at $50 \pm 5{ }^{\circ} \mathrm{C}$. Every $2 \mathrm{~h}, 102 \mathrm{~min}$ of radiation and $18 \mathrm{~min}$ of water spay were alternately carried out on the samples $(100 \mathrm{~mm} \times 100 \mathrm{~mm} \times 10 \mathrm{~mm})$. After 1000 cycles $(2000 \mathrm{~h})$, the samples were taken out of the chamber for further observation and evaluation of appearance.

\subsection{Materials}

Highly reactive metakaolin (trade name METAMAX) was purchased from BASF SE (Ludwigshafen, Germany). The chemical composition results of the metakaolin determined by X-ray fluorescence (XRF) is listed in Table 1. Industrial sodium silicate solution $\left(\mathrm{Na}_{2} \mathrm{O} \cdot \mathrm{nSiO}_{2}, n \approx 2.4\right.$, mass 
fraction $\mathrm{W}_{(\mathrm{Na} 2 \mathrm{O}+\mathrm{SiO} 2)} \% \approx 36 \%$ ) was obtained from Tongxiang Sunny Sodium Silicate Plant (Wuhan, China). Sodium hydroxide was purchased from SINOPHARM Chemical Reagent Co., Ltd. (Beijing, China). HMGB were purchased from 3M Company (trade name K1 and VS-5500, St. Paul, MN, USA). The main performance parameters of HMGB K1 and HMGB VS-5500 are listed in Table 2. Compared with HMGB K1, HMGB VS-5500 possessed a much higher compressive strength as well as a smaller diameter with more narrow size distribution. All of the above reagents were used as received without further modification.

Table 1. Chemical composition (wt \%) of metakaolin determined by X-ray Fluorescence (XRF).

\begin{tabular}{cccccccccc}
\hline $\mathrm{SiO}_{2}$ & $\mathrm{Al}_{2} \mathrm{O}_{3}$ & $\mathrm{Fe}_{2} \mathrm{O}_{3}$ & $\mathrm{CaO}$ & $\mathrm{K}_{2} \mathrm{O}$ & $\mathrm{Na}_{2} \mathrm{O}$ & $\mathrm{SO}_{3}$ & $\mathbf{P}_{2} \mathrm{O}_{5}$ & $\mathrm{TiO}_{2}$ & $\mathrm{ZrO}_{2}$ \\
\hline $53.75 \%$ & $43.82 \%$ & $0.45 \%$ & $0.16 \%$ & $0.18 \%$ & $0.26 \%$ & $0.02 \%$ & $0.43 \%$ & $0.86 \%$ & $0.029 \%$ \\
\hline
\end{tabular}

Table 2. Main performance parameters of HMGB K1 and HMGB VS-5500.

\begin{tabular}{|c|c|c|c|c|c|c|c|}
\hline \multirow{2}{*}{ HMGB } & \multirow{2}{*}{$\begin{array}{l}\text { Compressive } \\
\text { Strength (MPa) }\end{array}$} & \multirow{2}{*}{$\begin{array}{l}\text { Density } \\
\left(\mathrm{g} / \mathrm{cm}^{3}\right)\end{array}$} & \multicolumn{4}{|c|}{ Size Distribution ( $\mu \mathrm{m}$, Volume Ratio) } & \multirow{2}{*}{ Color } \\
\hline & & & 10 th $\%$ & 50 th $\%$ & 90th\% & Max & \\
\hline K1 & 1.72 & 0.125 & 30 & 65 & 110 & 120 & white \\
\hline VS-5500 & 37.9 & 0.38 & 15 & 40 & 75 & 85 & white \\
\hline
\end{tabular}

\subsection{Sample Preparation}

The basic formula of the alkali activated metakaolin-based geopolymer consisted of metakaolin, sodium hydroxide, sodium silicate, water and hollow micro-sphere glass beads (if needed). To explore the impact on the compressive strength of the geopolymer, we chose four components (metakaolin, sodium hydroxide, sodium silicate and water) as the three-level factors in an orthogonal experimental design demonstrated in Table 3. The samples were prepared by the following procedure. First, sodium hydroxide was dissolved in water to prepare a strong alkali solution. Sodium silicate solution was then added to the alkali solution and stirred for $5 \mathrm{~min}$ until the alkali solution cooled down to room temperature. After that, metakaolin or a mixture of metakaolin and HMGB were sieved into the alkali solution and stirred well to form a slurry paste. Finally, alkali activated metakaolin-based geopolymer was obtained after the curing procedure at different curing temperatures $\left(20^{\circ} \mathrm{C}, 40^{\circ} \mathrm{C}, 60^{\circ} \mathrm{C}, 80^{\circ} \mathrm{C}\right.$ and $\left.100{ }^{\circ} \mathrm{C}\right)$ and curing times $(24 \mathrm{~h}, 72 \mathrm{~h}$ and $168 \mathrm{~h}$ ) with an initial relative humidity of $50 \% \pm 5 \%$ during the first $12 \mathrm{~h}$.

Table 3. Factor level of orthogonal experiment design.

\begin{tabular}{ccccc}
\hline Factor Level & Metakaolin (g) & NaOH (g) & Sodium Silicate (g) & Water (g) \\
\hline 1 & 24 & 3 & 25 & 4 \\
2 & 25 & 4 & 26 & 5 \\
3 & 26 & 5 & 27 & 6 \\
\hline
\end{tabular}

\section{Results and Discussion}

\subsection{Formula of Alkali Activated Metakaolin-Based Geopolymer}

Multiple factors determine the properties, especially the compressive strength, of alkali activated geopolymers, such as the type and concentration of alkaline-activator, the proportion of raw materials, curing conditions, and so on. In this paper, we discuss the impact of four components on the mechanical properties of geopolymer. As demonstrated in Table 4, slurries of alkali activated metakaolin-based geopolymer were prepared according to the ratios of an L9 $\left(3^{4}\right)$ orthogonal arrays. Here, L9 $\left(3^{4}\right)$ represents an orthogonal test designed for four factors with three levels for each factor, as listed in 
Table 3. Specimens \#1 through \#9 of the prepared slurries were cured at $20{ }^{\circ} \mathrm{C}$ for seven days for compressive strength tests. In the compressive strength tests, three specimens were tested of each sample, for which the average compressive strength and standard deviation data are listed in Table 4. Based on the range analysis of the orthogonal experiment in Table 4, it is suggested that the content of the alkaline-activator, $\mathrm{NaOH}$, had the most important impact on the compressive strength, followed by the content of metakaolin, water and sodium silicate. Furthermore, it can be concluded from the range analysis that the optimal mass ratio of alkali activated metakaolin-based geopolymer was sample \#5, with the highest compressive strength of $37.4 \mathrm{MPa}$. Calculated from the chemical composition of raw materials, the oxide molar ratio of $\mathrm{SiO}_{2}: \mathrm{Al}_{2} \mathrm{O}_{3}: \mathrm{Na}_{2} \mathrm{O}: \mathrm{H}_{2} \mathrm{O}$ in sample $\# 5$ was 3.4:1.1:1.0:11.8. This ratio of sample preparation was adopted in further samples.

Table 4. Orthogonal experiment of alkali activated metakaolin-based geopolymer with different ratios.

\begin{tabular}{ccccccc}
\hline \multirow{2}{*}{ Sample } & Metakaolin & NaOH & Sodium Silicate & Water & $\begin{array}{c}\text { Compressive } \\
\text { Strength }\end{array}$ & $\begin{array}{c}\text { Standard } \\
\text { Deviation }\end{array}$ \\
\cline { 2 - 6 } & $\mathbf{( g )}$ & $\mathbf{( g )}$ & $\mathbf{( g )}$ & $\mathbf{( g )}$ & $\mathbf{( M P a )}$ & $\mathbf{( M P a )}$ \\
\hline$\# 1$ & 24.0 & 3.0 & 25.0 & 4.0 & 32.59 & 2.34 \\
$\# 2$ & 24.0 & 4.0 & 26.0 & 5.0 & 30.24 & 3.69 \\
$\# 3$ & 24.0 & 5.0 & 27.0 & 6.0 & 26.42 & 3.29 \\
$\# 4$ & 25.0 & 3.0 & 26.0 & 6.0 & 34.40 & 3.59 \\
$\# 5$ & 25.0 & 4.0 & 27.0 & 4.0 & 37.40 & 2.01 \\
$\# 6$ & 25.0 & 5.0 & 25.0 & 5.0 & 29.32 & 3.72 \\
$\# 7$ & 26.0 & 3.0 & 27.0 & 5.0 & 31.80 & 2.81 \\
$\# 8$ & 26.0 & 4.0 & 25.0 & 6.0 & 32.43 & 3.77 \\
$\# 9$ & 26.0 & 5.0 & 26.0 & 4.0 & 29.59 & 2.91 \\
\hline $\mathrm{K}_{1}{ }^{\mathrm{a}}$ & 89.25 & 98.78 & 94.33 & 99.58 & & \\
$\mathrm{~K}_{2}$ & 101.12 & 100.07 & 94.24 & 91.36 & & \\
$\mathrm{~K}_{3}$ & 93.82 & 85.34 & 95.62 & 93.25 & & \\
$\mathrm{k}_{1} \mathrm{~b}$ & 29.75 & 32.93 & 31.44 & 33.19 & & \\
$\mathrm{k}_{2}$ & 33.71 & 33.36 & 31.41 & 30.45 & & \\
$\mathrm{k}_{3}$ & 31.27 & 28.45 & 31.87 & 31.08 & & \\
$\mathrm{R}^{\mathrm{c}}$ & 3.96 & 4.91 & 0.46 & 2.74 & & \\
\hline
\end{tabular}

${ }^{\mathrm{a}} \mathrm{K}_{1}$ denoted the sum of level $1 ;{ }^{\mathrm{b}} \mathrm{k}_{1}$ denoted the average of level $1{ }^{\mathrm{c}} \mathrm{R}$ denoted the range.

\subsection{Influence of Curing Temperature and Time on the Properties of Alkali Activated Metakaolin-Based Geopolymer}

The performance of alkali activated metakaolin-based geopolymers are not only influenced by the chemical composition, dosage and concentration of raw materials but also by the curing conditions during the early-age polymerization process. In this paper, the influence of curing temperature and time on the properties of alkali activated metakaolin-based geopolymers will be discussed.

3.2.1. Influence of Curing Temperature and Time on the Compressive Strength of Alkali Activated Metakaolin-Based Geopolymers

As demonstrated in Figure 1, the relationship of compressive strength of alkali activated metakaolin-based geopolymers with curing temperature and time was studied at $20^{\circ} \mathrm{C}, 40^{\circ} \mathrm{C}, 60^{\circ} \mathrm{C}$, $80^{\circ} \mathrm{C}$ and $100{ }^{\circ} \mathrm{C}$ for 24 to $168 \mathrm{~h}$. The samples were prepared using the weight ratios referred to as sample \#5 in Section 3.1. After $24 \mathrm{~h}$ of thermal curing, all geopolymers had solidified from metakaolin paste to form rigid structures. However, it was found that the compressive strength was only $11.88 \mathrm{MPa}$ after $24 \mathrm{~h}$ of curing at $20^{\circ} \mathrm{C}$. This value increased to $37.41 \mathrm{MPa}$ after curing for $168 \mathrm{~h}$, which indicates that the polymerization rate of the geopolymer slurry was quite slow at relatively low temperatures [21]. The results also suggest that the best curing condition was $60^{\circ} \mathrm{C}$ for $168 \mathrm{~h}$, where the alkali activated metakaolin-based geopolymer showed the highest compressive strength at $52.26 \mathrm{MPa}$. 


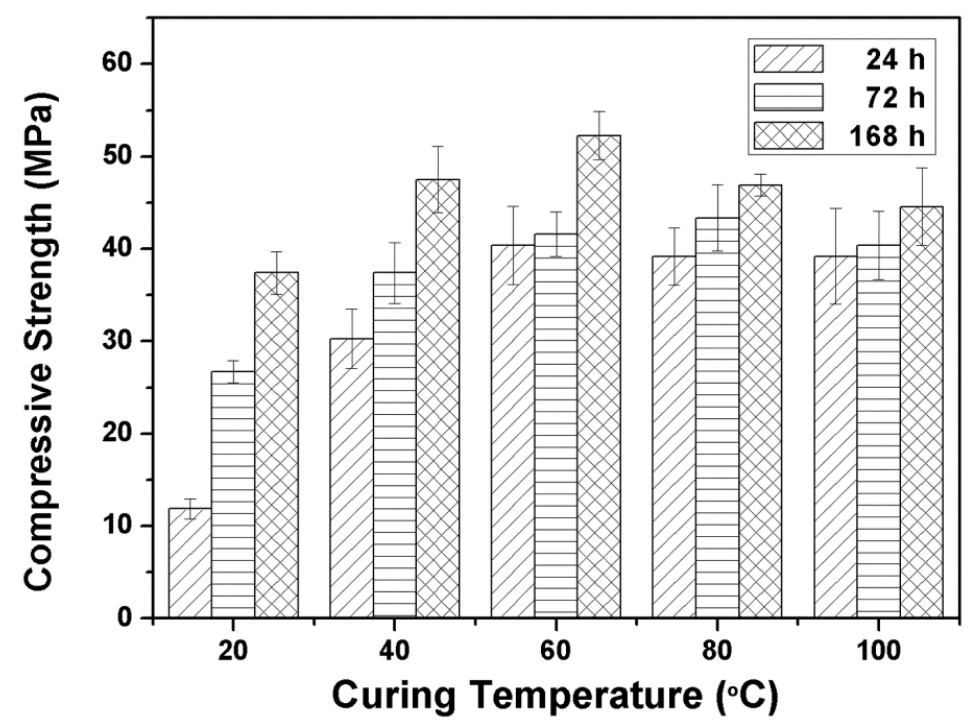

Figure 1. Effects of curing temperature and time on the compressive strength of alkali activated metakaolin-based geopolymer.

The increased curing temperature facilitates the dissolution of amorphous structures in metakaolin particles and promotes the formation and polymerization of the alkali-activation precursors, such as $\mathrm{OSi}(\mathrm{OH})_{3}{ }^{-}, \mathrm{Al}(\mathrm{OH})_{4}{ }^{-}$and $(\mathrm{OH})_{3}{ }^{-} \mathrm{Si}-\mathrm{O}-\mathrm{Al}-(\mathrm{OH})_{3}$ coordination structures [22]. In addition, raising the curing temperature is also advantageous to the exclusion of water in the reaction system, which accelerates the growth of the gel phase [21]. Although the metakaolin paste could not solidify in the initial $12 \mathrm{~h}$ at $20^{\circ} \mathrm{C}$, under higher temperature conditions, the metakaolin paste solidified within a short time to form rigid structures with great strength. In summary, the compressive strength of samples cured at a higher temperature are greater than those cured at a low temperature.

On the other hand, the dissolution of the amorphous structure of metakaolin particles becomes too fast at higher curing temperature conditions, e.g., $80{ }^{\circ} \mathrm{C}$ and $100{ }^{\circ} \mathrm{C}$. Stimulated by the alkali activator, polymerization between $\mathrm{Al}$ atoms in metakaolin and $\mathrm{Si}$ monomers or oligomers occurs rapidly, and metakaolin particles become sealed by a layer of geopolymer, preventing contact with the alkali activator [21]. In addition, when the curing temperature was high, the samples experienced a substantial loss of moisture, which is required for the geopolymer reaction to develop strength. We found the same trend reported in the literature, whereby increasing the curing temperature beyond $60{ }^{\circ} \mathrm{C}$ does not substantially increase the compressive strength after curing for $168 \mathrm{~h}[23,24]$.

3.2.2. Influence of Curing Temperature and Time on the Microstructure of Alkali Activated Metakaolin-Based Geopolymer

Figure 2 shows the $\mathrm{X}$-ray diffractograms of raw material metakaolin and geopolymers cured at different temperatures and times. In the XRD pattern of metakaolin, a wide dispersion peak located between $18^{\circ}$ and $25^{\circ}$ was attributed to the amorphous structure of metakaolin [25]. In addition to quartz crystals, the microstructure of metakaolin was mainly hypocrystalline and amorphous. After geopolymerization, all XRD patterns showed the typical amorphous structure of metakaolin geopolymer with a wide diffraction hump in the range of $20^{\circ}$ to $35^{\circ}(2 \theta)$, regardless of the curing condition differences. As assumed by Palomo et al. and Rahier et al., this dispersion peak can be attributed to the amorphous aluminosilicate gel, which is the primary binder phase present in geopolymeric systems [26,27]. In addition, characteristic diffraction peaks of quartz remained after geopolymerization, which suggests that quartz did not participate in the geopolymerization reaction while the amorphous structure of metakaolin transformed from one structure to another structure. This is mainly due to the low dissolution of crystalline quartz into alkaline media [28,29]. Nevertheless, 
the solid-phase reaction between reserved quartz, undissolved amorphous silicon and aluminum structures in metakaolin with unreacted alkali activator might continue for a considerable time. This might be a reason that the compressive strength of geopolymer continually increases over time [30].

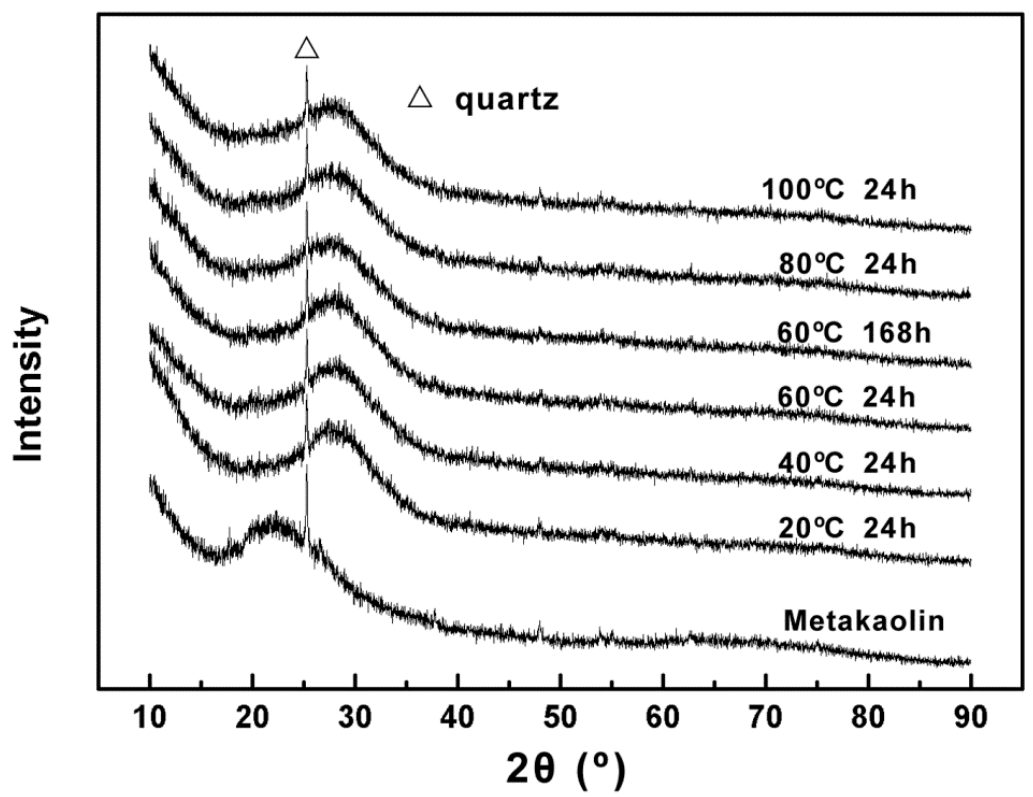

Figure 2. X-ray diffractograms of metakaolin and geopolymers cured at different temperatures and times.

From the study of mechanical properties of alkali activated metakaolin-based geopolymer, the compressive strength of geopolymer increased with temperature during the initial $24 \mathrm{~h}$ of curing. The compressive strength of geopolymer reached over $40 \mathrm{MPa}$ after $24 \mathrm{~h}$ curing at $60^{\circ} \mathrm{C}$, while it was only $11 \mathrm{MPa}$ at $20^{\circ} \mathrm{C}$. However, the distinctions between the X-ray diffractograms of the geopolymers cured at different temperatures were not obvious. In addition, although the compressive strength of geopolymer cured for $168 \mathrm{~h}$ was obviously higher than if cured for $24 \mathrm{~h}$ at $60^{\circ} \mathrm{C}$, the differences in $\mathrm{X}$-ray diffractograms were insignificant as well. It is suggested that the amorphous gel phase may be a major factor in the mechanical properties of alkali activated metakaolin-based geopolymers.

Figure 3 shows the FT-IR transmittance spectra of raw material metakaolin and the geopolymers cured at different temperatures for $24 \mathrm{~h}$. Due to the presence of water in metakaolin and the geopolymers, the strong characteristic peaks approximately $3450 \mathrm{~cm}^{-1}$ and $1650 \mathrm{~cm}^{-1}$ were attributed to stretching and bending vibrations of hydroxyl, respectively.

After geopolymerization, the chemical environment around regular arranged chain structures of the $\mathrm{Si}-\mathrm{O}$ bond altered, along with the formation of Al-O-Si bonds. Subsequently, the strong asymmetrical stretching vibration peak of the Si-O bond in metakaolin $\left(1100 \mathrm{~cm}^{-1}\right)$ all shifted to a lower wavenumber (to $1010 \mathrm{~cm}^{-1}$ ) for all the curing temperatures [31]. This indicated that the solidification process of the geopolymer is also a chemical reaction, with the generation of a new substance. In all the spectra of geopolymers, the bands at approximately $600 \mathrm{~cm}^{-1}$ were due to Al-O-Si stretching vibrations. Si-O-Si bending vibration at approximately $450 \mathrm{~cm}^{-1}$ was also present [32,33]. It was also found that the broad and strong peak at approximately $830 \mathrm{~cm}^{-1}$, which belongs to the stretching vibration of hexa-coordinate $\mathrm{Al}(\mathrm{VI})-\mathrm{OH}$ and $\mathrm{Al}(\mathrm{VI})-\mathrm{O}$ in metakaolin, almost disappeared after geopolymerization. A new peak at approximately $710 \mathrm{~cm}^{-1}$ from the bending vibration of tetra-coordinated $\mathrm{Al}(\mathrm{IV})-\mathrm{O}-\mathrm{Si}$ in a cyclic structure emerged on the FT-IR spectra of the geopolymers. This phenomenon signified the formation of aluminosilicate networks with the transition from hexa-coordinated $\mathrm{Al}(\mathrm{VI})$ to tetra-coordinated $\mathrm{Al}(\mathrm{IV})$ during the geopolymerization process, as observed by Sitarz et al. [34,35]. However, the transition was incomplete after $24 \mathrm{~h}$ of curing at $20^{\circ} \mathrm{C}$; 
therefore, the peak was not as sharp as in the higher curing temperature condition. In addition, after geopolymerization, all FT-IR spectra showed a shoulder at approximately $920 \mathrm{~cm}^{-1}$, due to $\mathrm{Al}$ (VI)-O residues, which proved that, after $24 \mathrm{~h}$, the geopolymerization was incomplete, regardless of the curing temperature [36].

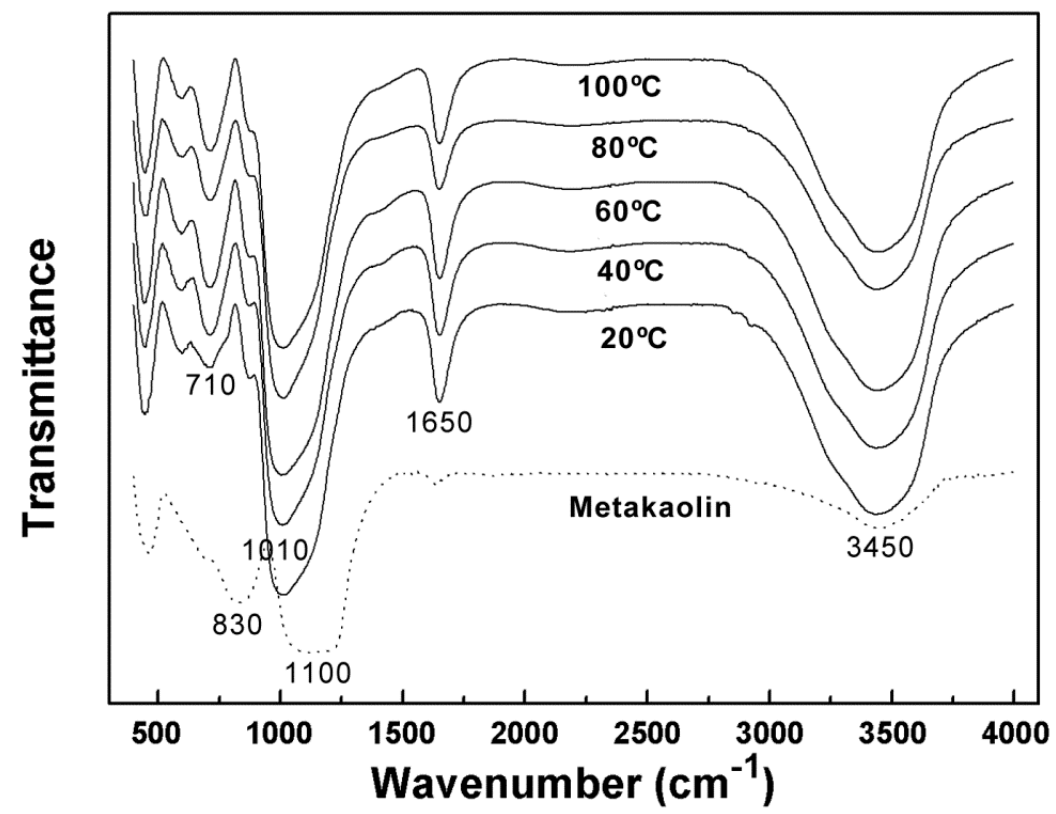

Figure 3. FT-IR spectra of metakaolin and geopolymers cured at different temperature for $24 \mathrm{~h}$.

Table 5 lists the wavenumber and transmittance of the peaks at approximately $1010 \mathrm{~cm}^{-1}$ and $710 \mathrm{~cm}^{-1}$, before and after curing at different temperatures. A smaller value of transmittance represents a higher peak intensity. It was found that after curing both the shifting extent and peak intensity were highest on the alkali activated metakaolin-based geopolymer cured at $60{ }^{\circ} \mathrm{C}$, although the difference was very slight. Therefore, it is speculated that the curing speed was fastest at $60^{\circ} \mathrm{C}$, which is consistent with the earlier study on the compressive strength of the geopolymers.

Table 5. Detailed data about the transmittance peak approximately $1010 \mathrm{~cm}^{-1}$ and $710 \mathrm{~cm}^{-1}$.

\begin{tabular}{|c|c|c|c|c|}
\hline \multirow{2}{*}{$\begin{array}{c}\text { Curing } \\
\text { Temperature }\left({ }^{\circ} \mathrm{C}\right)\end{array}$} & \multicolumn{2}{|c|}{$\begin{array}{l}\text { Transmittance Peak at Approximately } \\
\qquad 1010 \mathrm{~cm}^{-1}\end{array}$} & \multicolumn{2}{|c|}{$\begin{array}{l}\text { Transmittance Peak at Approximately } \\
\qquad 710 \mathrm{~cm}^{-1}\end{array}$} \\
\hline & Wavenumber $\left(\mathrm{cm}^{-1}\right)$ & Transmittance & Wavenumber $\left(\mathrm{cm}^{-1}\right)$ & Transmittance \\
\hline None & 1110 & 0.415 & 831 & 0.578 \\
\hline 20 & 1018 & 0.053 & 715 & 0.796 \\
\hline 40 & 1014 & 0.082 & 713 & 0.702 \\
\hline 60 & 1008 & 0.045 & 709 & 0.656 \\
\hline 80 & 1014 & 0.095 & 717 & 0.742 \\
\hline 100 & 1012 & 0.059 & 715 & 0.702 \\
\hline
\end{tabular}

\subsection{Alkali Activated Metakaolin-Based Geopolymer for Thermal Insulation}

The traditional method for improving insulation in geopolymers is to introduce hole structures by physical or chemical methods, to produce geopolymers with high porosity and thus better thermal insulation. Aluminum powder, hydrogen peroxide, surfactant, polystyrene foam and high temperature are commonly used approaches. To further reduce the thermal conductivity of porous geopolymers, the bubbles should be more homogenous and closed. HMGBs are a novel filler for thermal insulation materials that contain vacuum rarefied gas inside glass beads and, unlike traditional foaming agents, feature light-weight, large volume, low thermal conductivity, controllable particle size distribution, 
high compressive strength, excellent dispersibility and fluidity, chemical inertness, and so on [37]. In this paper, HMGB K1 and HMGB VS-5500 were mixed with metakaolin particles to improve the thermal insulation properties of alkali activated metakaolin-based geopolymer based on different volume ratios with metakaolin. Excluding HMGB, the samples were set with the weight ratios referred to as sample \#5 in Section 3.1.

As shown in Figure 4, the internal morphologies of alkali activated metakaolin-based geopolymers with different ratios of HMGB were studied by SEM after curing at $60^{\circ} \mathrm{C}$ for $168 \mathrm{~h}$. Images of Ka-Ke display the geopolymer with HMGB K1, with the volume ratio of metakaolin to HMGB K1 of 10:1, 8:1, 6:1, 4:1 and 2:1. Similarly, images of Va-Ve display the geopolymer with HMGB VS-5500 and the volume ratio of metakaolin to HMGB K1 of 10:1, 8:1, 6:1, 4:1 and 2:1. From the SEM images, we can see that the HMGB were distributed across the compact microstructures of the matrix of alkali activated metakaolin-based geopolymer randomly. An almost continuous matrix from the geopolymer paste to the glass beads can be observed, demonstrating a good interface between the two. However, some microcracks were observed in both HMGB samples. Such cracks could be reasonably imputed to the curing process, due to the constraining effect exerted by the glass spheres to the shrinkage of the paste [29]. With the increased admixing amount of HMGB, the distribution of sphere structures became denser and uniform. Since the average diameter of HMGB VS-5500 was smaller than that of HMGB K1, with a narrower size distribution, the spheres distributed more densely on the HMGB VS-5500 modified samples.

As the two important properties of thermal insulation materials, the thermal conductivity and compressive strength of alkali activated metakaolin-based geopolymers and HMGB modified geopolymers were tested after curing at $60^{\circ} \mathrm{C}$ for $168 \mathrm{~h}$ [38]. As illustrated in Figure 5, the thermal conductivity and compressive strength of as-prepared alkali activated metakaolin-based geopolymers was $0.88 \mathrm{~W} / \mathrm{mK}$ and $52.2 \mathrm{MPa}$, respectively. As the volume ratio of added metakaolin to HMGB $\mathrm{K} 1$ decreased from $10: 1$ to $2: 1$, the thermal conductivity reduced from $0.66 \mathrm{~W} / \mathrm{mK}$ to $0.37 \mathrm{~W} / \mathrm{mK}$. However, the compressive strength also declined from $45 \mathrm{MPa}$ (10:1) to $26 \mathrm{MPa}(2: 1)$. The decrease of conductivity of the geopolymer was achieved by the existence of air bubbles introduced by HMGB; the higher the HMGB content, the lower the thermal conductivity. However, the addition of HMGB $\mathrm{K} 1$ led to a dramatic decline in compressive strength of the geopolymeric system. The compressive strength of HMGB K1 is only $1.72 \mathrm{MPa}$. Similarly, as the volume ratio of metakaolin to HMGB VS-5500 decreased from 10:1 to 2:1, the thermal conductivity and compressive strength of alkali activated metakaolin-based geopolymer reduced from $0.57 \mathrm{~W} / \mathrm{mK}$ and $51 \mathrm{MPa}(10: 1)$ to $0.21 \mathrm{~W} / \mathrm{mK}$ and $42 \mathrm{MPa}$ (2:1). Due to the high compressive strength of HMGB VS-5500 (37.9 MPa) compared to HMGB K1, the decline of compressive strength in alkali activated metakaolin-based geopolymer with HMGB VS-5500 was much less obvious. In addition, the average diameter and density of HMGB VS-5500 was smaller than that of HMGB K1 with a narrower size distribution. Therefore, as demonstrated by the SEM studies, the more extensively distributed spheres in the HMGB VS-5500 modified samples may be the reason why the geopolymer showed a lower thermal conductivity, in spite of their higher density compared to K1.

From Figure $5 \mathrm{a}, \mathrm{b}$, it was interesting to find that the compressive strength curve of both HMGB K1 and HMGB VS-5500 modified samples showed a small raised plateau, before declining to the 6:1 volume ratio of metakaolin to HMGB. This could be due to the unique internal structure and stress distribution around this volume ratio, but the specific causes of this phenomenon need further investigation. The above data indicate that better thermal insulation properties but lower compressive strength can be expected with the increased content of HMGB. Therefore, a proper volume ratio of metakaolin to HMGB should be determined, in order to balance thermal insulation effects and mechanical properties. Based upon the conditions studied in this paper, the 6:1 volume ratio of metakaolin to HMGB VS-55001 was the most suitable, with a thermal conductivity of $0.37 \mathrm{~W} / \mathrm{mK}$ and compressive strength of $50 \mathrm{MPa}$. 

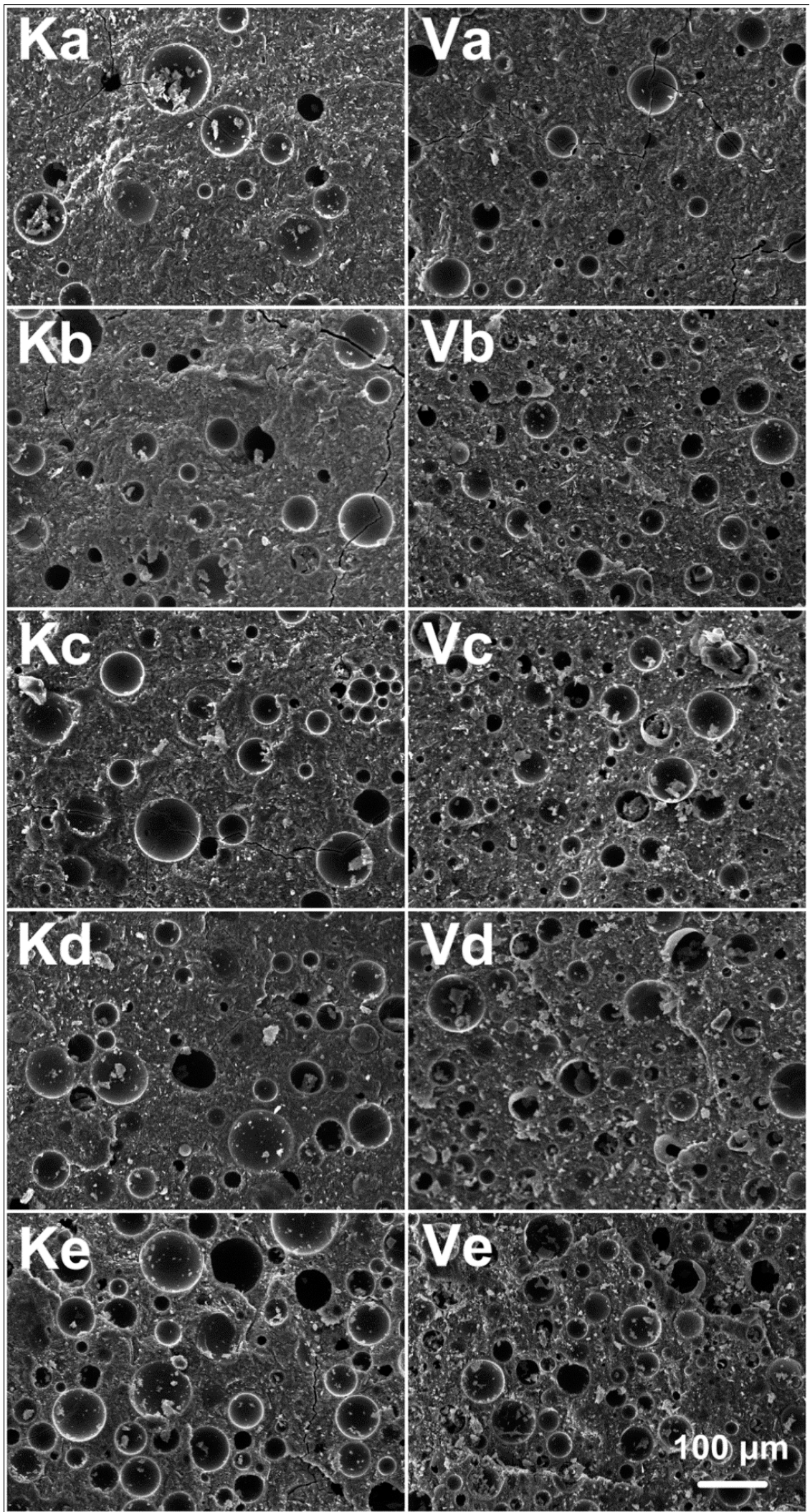

Figure 4. Internal morphologies of alkali activated metakaolin-based geopolymers with different ratios of HMGB: Ka-Ke denote the volume ratios of metakaolin to HMGB K1 of 10:1, 8:1, 6:1, 4:1 and 2:1, respectively; Va-Ve denote the volume ratios of metakaolin to HMGB VS-5500 of 10:1, 8:1, 6:1, 4:1 and 2:1, respectively. Scale bar indicates $100 \mu \mathrm{m}$. 

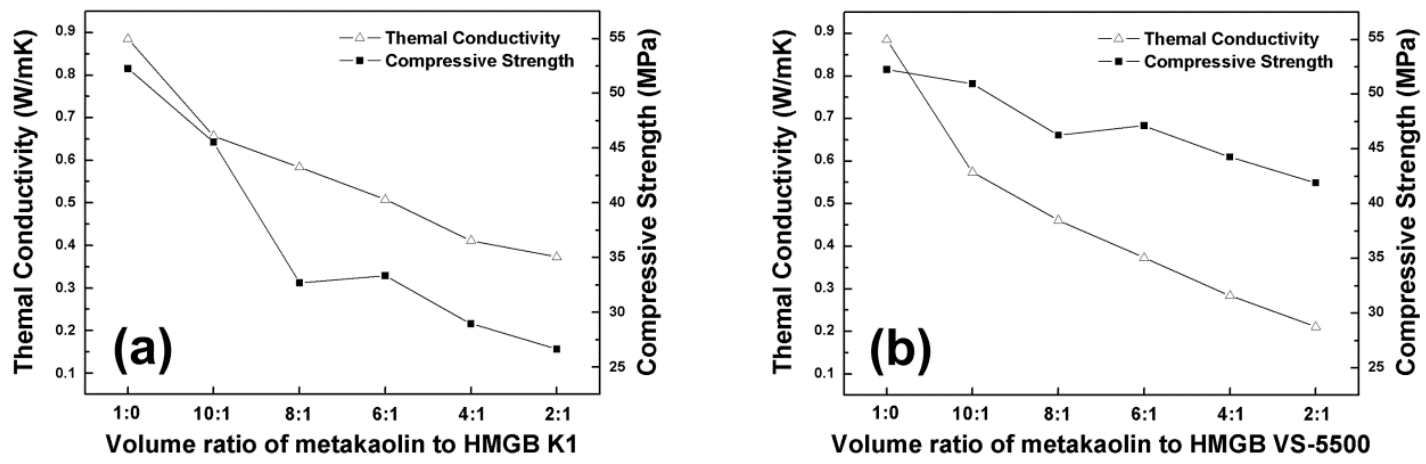

Figure 5. Thermal conductivity and compressive strength of alkali activated metakaolin-based geopolymers with different ratios of HMGB: (a) HMGB K1 and (b) HMGB VS-5500.

One potential application of prepared glass bead modified geopolymer with low thermal conductivity is as a coating for concrete surface insulation protection. We explored the interfacial properties and durability of prepared glass bead modified geopolymer as a coating on concrete. The geopolymer containing HMGB VS-5500 was coated on a concrete surface with a thickness of $5 \mathrm{~mm}$. After curing at $60{ }^{\circ} \mathrm{C}$ for $168 \mathrm{~h}$, the cross section between the geopolymer based thermal insulation coating and concrete was studied by SEM. As illustrated in Figure 6, the coating adhered closely to the concrete, without any interspaces. Glass beads were also observed in the coating. In addition, the adhesive strength between the coating of geopolymer containing HMGB VS-5500 and concrete was $3.76 \mathrm{MPa}$. Artificial weathering aging tests were used to evaluate the durability of the geopolymer based thermal insulation coating. After 1000 cycles of irradiance and water spray alternation, the geopolymer showed excellent durability without any crushing or shelling. Although the curing condition was not feasible as it stands, it is believed that by adjusting the curing condition to milder conditions, as-prepared alkali activated metakaolin-based geopolymer could find widespread applications in concrete thermal protection.

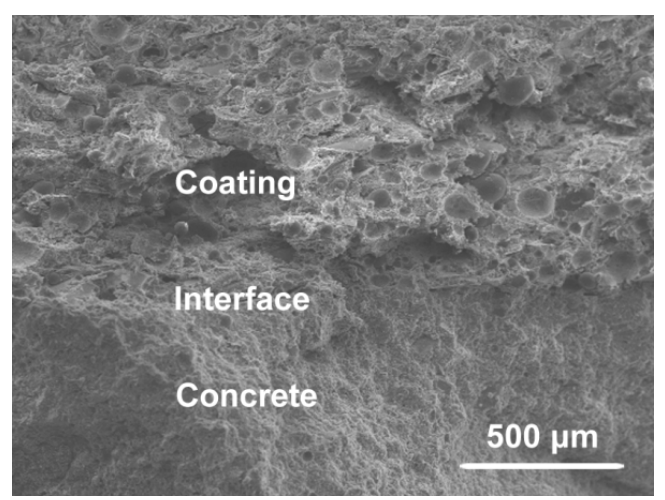

Figure 6. Cross section between geopolymer based thermal insulation coating and concrete. Scale bar indicated $500 \mu \mathrm{m}$.

\section{Conclusions}

In this paper, the preparation and properties of alkali activated metakaolin-based geopolymer were studied. It was found that the optimal geopolymer was prepared with metakaolin, sodium hydroxide, sodium silicate and water, using the weight ratios of $41.6 \%, 6.7 \% 45.0 \%$ and $6.7 \%$, respectively. In addition, the best curing condition was found to be $60{ }^{\circ} \mathrm{C}$ for $168 \mathrm{~h}$, where the alkali activated metakaolin-based geopolymer showed the highest compression strength at $52.26 \mathrm{MPa}$. The amorphous gel phase is the major factor in the mechanical properties of alkali activated metakaolin-based geopolymers. In addition, this result also suggests that a suitable volume ratio of 
metakaolin to hollow micro-sphere glass beads in alkali activated metakaolin-based geopolymers is 6:1, which achieved a thermal conductivity of $0.37 \mathrm{~W} / \mathrm{mK}$ and compressive strength of $50 \mathrm{MPa}$.

Acknowledgments: This work was financially supported by the Non-Profit Industry Research Special Funds Program of the Ministry of Water Resources of China (Grant No. 201301023), the Young Talent Funded Projects of the Chinese Hydraulic Engineering Society, the Basic Research Funds Program of Changjiang River Scientific Research Institute (Grant No. CKSF2016001/CL), and the National Natural Science Foundation of China (Grant No. 51309018). The authors also would like to thank the Innovation Team of Changjiang River Scientific Research Institute for their support.

Author Contributions: Liang Chen and Zaiqin Wang conceived and designed the experiments; Yuanyi Wang and Jing Feng performed the experiments; Zaiqin Wang and Jing Feng analyzed the data; Yuanyi Wang and Liang Chen wrote the paper.

Conflicts of Interest: The authors declare no conflict of interest.

\section{References}

1. Duxson, P.; Provis, J.L.; Lukey, G.C.; Van Deventer, J.S.J. The role of inorganic polymer technology in the development of 'green concrete'. Cem. Concr. Res. 2007, 37, 1590-1597. [CrossRef]

2. Rashad, A.M. Metakaolin as cementitious material: History, scours, production and composition-A comprehensive overview. Constr. Build. Mater. 2013, 41, 303-318. [CrossRef]

3. Yan, D.; Chen, S.; Zeng, Q.; Xu, S.; Li, H. Correlating the elastic properties of metakaolin-based geopolymer with its composition. Mater. Des. 2016, 95, 306-318. [CrossRef]

4. Zivica, V.; Balkovic, S.; Drabik, M. Properties of metakaolin geopolymer hardened paste prepared by high-pressure compaction. Constr. Build. Mater. 2011, 25, 2206-2213. [CrossRef]

5. Martin, A.; Pastor, J.Y.; Palomo, A.; Fernandez Jimenez, A. Mechanical behaviour at high temperature of alkali-activated aluminosilicates (geopolymers). Constr. Build. Mater. 2015, 93, 1188-1196. [CrossRef]

6. Temuujin, J.; Rickard, W.; Lee, M.; van Riessen, A. Preparation and thermal properties of fire resistant metakaolin-based geopolymer-type coatings. J. Non-Cryst. Solids 2011, 357, 1399-1404. [CrossRef]

7. Azimi, E.A.; Al Bakri Abdullah, M.M.; Liew Yun, M.; Heah Cheng, Y.; Hussin, K.; Aziz, I.H. Review of geopolymer materials for thermal insulating applications. Key Eng. Mater. 2015, 660, 17-22. [CrossRef]

8. Zhang, Z.; Provis, J.L.; Reid, A.; Wang, H. Mechanical, thermal insulation, thermal resistance and acoustic absorption properties of geopolymer foam concrete. Cem. Concr. Compos. 2015, 62, 97-105. [CrossRef]

9. Temuujin, J.; Minjigmaa, A.; Rickard, W.; Lee, M.; Williams, I.; van Riessen, A. Preparation of metakaolin based geopolymer coatings on metal substrates as thermal barriers. Appl. Clay Sci. 2009, 46, 265-270. [CrossRef]

10. Fernandez-Jimenez, A.; Monzo, M.; Vicent, M.; Barba, A.; Palomo, A. Alkaline activation of metakaolin-fly ash mixtures: Obtain of zeoceramics and zeocements. Microporous Mesoporous Mater. 2008, 108, 41-49. [CrossRef]

11. Duxson, P.; Lukey, G.C.; van Deventer, J.S.J. Physical evolution of na-geopolymer derived from metakaolin up to 1000 degrees c. J. Mater. Sci. 2007, 42, 3044-3054. [CrossRef]

12. Cheng, T.W.; Lee, M.L.; Ko, M.S.; Ueng, T.H.; Yang, S.F. The heavy metal adsorption characteristics on metakaolin-based geopolymer. Appl. Clay Sci. 2012, 56, 90-96. [CrossRef]

13. Kong, D.L.Y.; Sanjayan, J.G.; Sagoe-Crentsil, K. Factors affecting the performance of metakaolin geopolymers exposed to elevated temperatures. J. Mater. Sci. 2008, 43, 824-831. [CrossRef]

14. Duxson, P.; Provis, J.L.; Lukey, G.C.; Mallicoat, S.W.; Kriven, W.M.; van Deventer, J.S.J. Understanding the relationship between geopolymer composition, microstructure and mechanical properties. Colloids Surf. Physicochem. Eng. Asp. 2005, 269, 47-58. [CrossRef]

15. Roviello, G.; Menna, C.; Tarallo, O.; Ricciotti, L.; Ferone, C.; Colangelo, F.; Asprone, D.; di Maggio, R.; Cappelletto, E.; Prota, A.; et al. Preparation, structure and properties of hybrid materials based on geopolymers and polysiloxanes. Mater. Des. 2015, 87, 82-94. [CrossRef]

16. Zhou, W.; Yan, C.; Duan, P.; Liu, Y.; Zhang, Z.; Qiu, X.; Li, D. A comparative study of high- and low- $\mathrm{Al}_{2} \mathrm{O}_{3}$ fly ash based-geopolymers: The role of mix proportion factors and curing temperature. Mater. Des. 2016, 95, 63-74. [CrossRef]

17. Rieger, D.; Kovarik, T.; Riha, J.; Medlin, R.; Novotny, P.; Belsky, P.; Kadlec, J.; Holba, P. Effect of thermal treatment on reactivity and mechanical properties of alkali activated shale-slag binder. Constr. Build. Mater. 2015, 83, 26-33. [CrossRef] 
18. Muniz-Villarreal, M.S.; Manzano-Ramirez, A.; Sampieri-Bulbarela, S.; Ramon Gasca-Tirado, J.; Reyes-Araiza, J.L.; Rubio-Avalos, J.C.; Perez-Bueno, J.J.; Apatiga, L.M.; Zaldivar-Cadena, A.; Amigo-Borras, V. The effect of temperature on the geopolymerization process of a metakaolin-based geopolymer. Mater. Lett. 2011, 65, 995-998. [CrossRef]

19. Yahya, Z.; Bakri, A.M.M.A.; Kamarudin, H.; Nizar, K.; Rafiza, A.R. Reviews on the Geopolymer Materials for Coating Application. Adv. Mater. Res. 2013, 626, 958-962.

20. Wiyono, D.; Antoni; Hardjito, D. Improving the Durability of Pozzolan Concrete Using Alkaline Solution and Geopolymer Coating. Procedia Eng. 2015, 125, 747-753. [CrossRef]

21. Rovnanik, P. Effect of curing temperature on the development of hard structure of metakaolin-based geopolymer. Constr. Build. Mater. 2010, 24, 1176-1183. [CrossRef]

22. Turker, H.T.; Balcikanli, M.; Durmus, I.H.; Ozbay, E.; Erdemir, M. Microstructural alteration of alkali activated slag mortars depend on exposed high temperature level. Constr. Build. Mater. 2016, 104, 169-180. [CrossRef]

23. Bakri, A.M.M.A.; Kamarudin, H.; BinHussain, M.; Nizar, I.K.; Zarina, Y.; Rafiza, A.R. The Effect of Curing Temperature on Physical and Chemical Properties of Geopolymers. Phys. Procedia 2011, 22, 286-291. [CrossRef]

24. Aredes, F.G.M.; Campos, T.M.B.; Machado, J.P.B.; Sakane, K.K.; Thim, G.P.; Brunell, D.D. Effect of cure temperature on the formation of metakaolinite-based geopolymer. Ceram. Int. 2015, 41, 7302-7311. [CrossRef]

25. Zhang, Y.; Zhang, W.; Sun, W.; Li, Z.; Liu, Z. Preparation of metakaolin based geopolymer and its three-dimensional pore structural characterization. J. Wuhan Univ. Technol. Mater. Sci. Ed. 2015, 30, 550-555. [CrossRef]

26. Palomo, A.; Glasser, F.P. Chemically-bonded cementitious materials based on metakaolin. Br. Ceram. Trans. J. 1992, 91, 107-112.

27. Rahier, H.; Mele, B.B.; Biesemans, M.; Wastiels, J.; Wu, X. Low-temperature synthesized aluminosilicate glasses. J. Mater. Sci. 1996, 31, 71-79. [CrossRef]

28. Choquette, M.; Berube, M.A.; Locat, L. Behaviour of common rock-forming minerals in a strongly basic $\mathrm{NaOH}$ solution. Can. Mineral. 1991, 29, 163-173.

29. Palmero, P.; Formia, A.; Antonaci, P.; Brini, S.; Tulliani, J.-M. Geopolymer technology for application-oriented dense and lightened materials. Elaboration and characterization. Ceram. Int. 2015, 41, 12967-12979. [CrossRef]

30. Zhang, S.Z.; Gong, K.C. Geopolymer. Mater. Sci. Eng. 2003, 3, 430-436.

31. Tippayasam, C.; Balyore, P.; Thavorniti, P.; Kamseu, E.; Leonelli, C.; Chindaprasirt, P.; Chaysuwan, D. Potassium alkali concentration and heat treatment affected metakaolin-based geopolymer. Constr. Build. Mater. 2016, 104, 293-297. [CrossRef]

32. Forst, R.L.; Fredericks, P.M.; Shurvell, H.F. Raman microscopy of some kaolinite clay minerals. Can. J. Appl. Spectrosc. 1996, 41, 10-14.

33. Parker, R.W.; Forst, R.L. The application of drift spectroscopy to the multicomponent analysis of organic chemicals adsorbed on montmorillonite. Clays Clay Miner. 1996, 44, 32-40. [CrossRef]

34. Sitarz, M.; Handke, M.; Mozgawa, W. Identification of silicooxygen rings in $\mathrm{SiO}_{2}$ based on IR spectra. Spectrochim. Acta A 2000, 56, 1819-1823. [CrossRef]

35. Sitarz, M.; Handke, M.; Mozgawa, W.; Galuskin, E.; Galuskina, I. The non-ring cations influence on silicooxygen ring vibrations. J. Mol. Struct. 2000, 555, 357-362. [CrossRef]

36. Lancellotti, I.; Catauro, M.; Ponzoni, C.; Bollino, F.; Leonelli, C. Inorganic polymers from alkali activation of metakaolin: Effect of setting and curing on structure. J. Solid State Chem. 2013, 200, 341-348. [CrossRef]

37. Aziz, I.H.; Al Bakri Abdullah, M.M.; Heah Cheng, Y.; Liew Yun, M.; Hussin, K.; Azimi, E.A. A review on mechanical properties of geopolymer composites for high temperature application. Key Eng. Mater. 2015, 660, 34-38. [CrossRef]

38. Salahuddin, M.B.M.; Norkhairunnisa, M.; Mustapha, F. A review on thermophysical evaluation of alkali-activated geopolymers. Ceram. Int. 2015, 41, 4273-4281. [CrossRef]

(C) 2016 by the authors; licensee MDPI, Basel, Switzerland. This article is an open access article distributed under the terms and conditions of the Creative Commons Attribution (CC-BY) license (http:/ / creativecommons.org/licenses/by/4.0/). 